\title{
A Gênese da educação grega: da areté homérica à Paideia clássica
}

Paulo Eduardo Vieira ${ }^{1}$

\section{Resumo}

O artigo apresenta a gênese da educação grega e do ideal de formação do homem grego, por meio da compreensão do conceito de areté homérica e do o conceito de Paideia política. De acordo com Nunes (2017) "A Paideia grega configura uma vibrante forma de entender e de organizar a sociedade e a cultura humana". (NUNES, 2017, p.2a). Contextualiza dois momentos históricos: o primeiro sobre transição da educação homérico para a educação pré-socrática ou cosmológico (do final do século VII ao final do século V a.C.), cujo momento representa a mudança da ateré homérica para a Paideia política; e o segundo momento sobre a educação no período socrático ou antropológico (do final do século $\mathrm{V}$ até o século IV a. C), no qual se consolida Paideia política ou filosófica. Fundamenta-se na tradição epistemológica e política do materialismo histórico e dialético. Trata-se de estudo bibliográfico e histórico-crítico. Parte da análise das condições materiais, ou seja, as condições econômicas, sociais, políticas e históricas da transição da Paideia homérica para a Paideia política. Considera que no período primitivo e no período clássico grego constituiu-se o ideário do homem heroico e político. A educação é o princípio por meio do qual a comunidade humana conserva e transmite a sua peculiaridade física e espiritual.

Palavras-chave: Educação. Filosofia. Paideia. Política.

\section{Resumen}

El artículo presenta la génesis de la educación griega y del ideal de formación del hombre griego, por medio de la comprensión del concepto de areté homérico y del concepto de Paideia política. De acuerdo con Nunes (2017) "La Paideia griega configura una vibrante forma de entender y de organizar la sociedad y la cultura humana". (NUNES, 2017, p.2a). Comprende dos momentos históricos: el primero sobre la transición de la educación homérica a la educación pre-socrática o cosmológica (de finales del siglo VII al final del siglo $\mathrm{V}$ a. C.), cuyo momento representa el cambio de la aterrizaje homérico a la Paideia política; y el segundo momento sobre la educación en el período socrático o antropológico (de finales del siglo $\mathrm{V}$ hasta el siglo $\mathrm{IV} \mathrm{aC}$ ), en el que se consolida Paideia política o filosófica. Se fundamenta en la tradición epistemológica y política del materialismo histórico y dialéctico. Se trata de un estudio bibliográfico e histórico-crítico. Parte del análisis de las condiciones materiales, es decir, las condiciones económicas, sociales, políticas e históricas de la transición de la Paideia homérica a la Paideia política. Considera que en el período primitivo y en el período clásico griego se constituyó el ideario del hombre heroico y político. La educación es el principio por el cual la comunidad humana conserva y transmite su peculiaridad física y espiritual.

Palabras-clave: Educacion. Filosofia. Paideia. Ética.

\footnotetext{
${ }^{1}$ Pesquisador do Grupo de Estudos e Pesquisas PAIDEIA e UNIFEG E-mail: pevieirahistoria@ hotmail.com
} 


\section{Introdução}

presente pesquisa tem o objetivo de investigar a gênese da
educação grega e o ideal de formação do homem grego, por
meio da compreensão do conceito de areté homérica e do o conceito de Paideia política. De acordo com Nunes (2017) “A Paideia grega configura uma vibrante forma de entender e de organizar a sociedade e a cultura humana". (NUNES, 2017, p.2a).

Sendo assim, dividimos a nossa pesquisa em dois momentos históricos: o primeiro sobre transição da educação homérico para a educação pré-socrática ou cosmológico (do final do século VII ao final do século V a.C.), cujo momento representa a mudança da ateré homérica para a Paideia política; e o segundo momento sobre a educação no período socrático ou antropológico (do final do século $\mathrm{V}$ até o século IV a. $\mathrm{C}$ ), no qual se consolida Paideia política ou filosófica.

Nesse sentido, destacamos esse recorte cronológico, a partir das considerações de Fonseca (1998, p. 1), a qual concebe o

[...] período antigo, que compreende a educação homérica e a educação antiga de Esparta e Atenas, e o novo período, o da educação no "século de Péricles", correspondendo este ao período áureo da cultura grega, o qual se inicia com os Sofistas e se desenvolverá com os filósofos/educadores ou educadores/filósofos gregos Sócrates, Platão e Aristóteles.

Enfim, o nosso intuito não é esgotar o tema de pesquisa aqui selecionado, mas demonstrar um ponto de vista sobre a importância e a influência da educação grega para o mundo ocidental. Para investigarmos a gênese da educação grega, utilizaremos como metodologia de pesquisa o materialismo histórico e dialético. As pesquisas dialéticas se fundamentam na lógica interna do processo e nos métodos que explicitam a dinâmica e as contradições internas dos fenômenos e evidenciam as relações entre homem-natureza, entre reflexão-ação e entre teoria-prática integrando elementos gnosiológicos, lógicos e ontológicos.

Desse modo, a pesquisa de natureza dialética, no campo da Filosofia, História e Educação, será o nosso caminho para a investigação sobre a 
gênese da educação grega, pois a dialética se situa, no plano da realidade, no plano histórico, "sob a forma da trama de relações contraditórias, conflitantes, de leis de construção, desenvolvimento e transformação dos fatos, sob as categorias totalidade, contradição, mediação, ideologia e práxis". (FRIGOTTO, in FAZENDA, 1994, p. 76).

Por meio dessa matriz epistemológica, usaremos como fonte de pesquisa para abordar a contribuição da educação grega os estudos de cunho bibliográfico com aparte teórico de livros, as publicações em periódicos, artigos científicos e outros.

\section{A educação no período homérico}

Para investigarmos a gênese da educação grega, precisaremos compreender a tradição mitológica do período homérico (século XV a VIII a.C.), no qual emerge o ideal de homem grego, através da compreensão do conceito de aretê.

Segundo Nunes (2017),

[...] a tradição mítica, de base rural, derivada de Homero e Hesíodo, definida como educação arcaica, chamada também de paideia antiga, que consistia em buscar formar a aristocracia grega nos critérios de exaltação da coragem bélica e heroica, em elogiar a preparação para a guerra, para o cuidado da casa, treinar para o sucesso no exercício dos negócios particulares. [...] Paideia configurava as lições dos adultos que preparavam os jovens para a aquisição da força, para a valentia, a destreza, a busca permanente da coragem, o estrito senso do dever e de honra que convêm aos guerreiros. (NUNES, 2017, p. 61)

Nesse contexto, a educação grega é constituída a partir do mito. E este não é procura responder questões pontuais, como surgiu o mundo? Como surgiram os seres humanos? E como formar o ser humano “perfeito"?

Dessa forma, segundo Marcondes (2008, p.20),

o mito configura assim a própria visão de mundo dos indivíduos, a sua maneira mesmo de vivenciar esta realidade. Nesse sentido, o pensamento mítico pressupõe a adesão e a aceitação dos indivíduos, na medida em que constitui as formas da experiência do real. $O$ mito não se justifica, não se fundamenta, 
portanto, nem se presta ao questionamento, a crítica ou a correção.

Nesse sentido, o mito é, portanto, uma produção coletiva, na qual as pessoas que vivem em sociedade e compartilham de certos arquétipos, que são aceitos e assimilados por um grupo de indivíduos, constituem, assim, o seu ethos, por meio das explicações de mundo, tais como origem do universo e origem da natureza, porém sem um questionamento crítico destas explicações, contribuindo para a "invenção das tradições".

Desse modo, o mito se constitui enquanto discurso, na tentativa de compreender a realidade, na qual as pessoas estão inseridas, expressando valores comuns a esta sociedade e que devem ser transmitidos para as futuras gerações, por meio da repetição de normas e valores de comportamentos. Assim, para os gregos do período homérico era fundamental o conhecimento dos mitos, pois o mito representava a identidade de um povo.

Logo, segundo Marcondes (2008, p.20) o pensamento mítico procura compreender a realidade social a partir de dois elementos centrais:

o apelo ao sobrenatural e ao mistério, ao sagrado e à magia, pois as causas dos fenômenos naturais, o que acontece com os homens, tudo é "governado por uma realidade exterior" ao mundo humano e natural, superior, misterioso, divina.

Nesse sentido, pretendemos compreender como as pessoas aprendiam os mitos no período homérico? E qual era a importância dos poetas e das rapsódias para a transmissão dos valores culturais dos gregos arcaicos?

De acordo com Jaeger (2013, p.23), para estudarmos a educação grega do período homérico, precisamos investigar o conceito de areté, pois "não se pode utilizar a história da palavra Paideia como fio condutor para estudar a origem da educação grega, porque esta palavra só aparece no séc. V a.C."

Portanto, de acordo com Jaeger (2013, p.23), para estudarmos o sentido mais antigo atribuído a educação grega, precisamos recorrer ao 
conceito de aretê, pois "o tema essencial da história da educação grega é [...] o conceito de areté que remonta aos tempos mais antigos". Por outro lado, de acordo com Fonseca (1998), é o conceito de areté "que exprime a forma primeira, original e originária, do ideal educativo grego". (FONSECA, 1998, p. 2)

Nesse sentido, investigaremos o conceito de areté presente na obra Ilíada e a Odisseia (séc. IX a.C.), atribuída ao poeta Homero. Estas obras são consideradas as principais fontes históricas que podemos encontrar as representações do ideal de formação do homem grego.

Portanto, é em Homero e nos chamados poemas homéricos que o ideal educativo do homem grego aparece originalmente formulado e explicitado, por meio do conceito de areté. Trata-se de um ideal transmitido de forma oral, por meio dos poetas, a partir dos quais podemos notar os valores que um homem heroico, aristocrata, guerreiro e político de destaque deveria possuir nesse momento. Posteriormente, no século de Platão, amplia-se a compreensão do Homem para o âmbito do Estado e da Educação.

Desse modo, na Ilíada o ideal homérico de homem grego, pode ser encontrado em personagens heroicos, tais como: “Agamémnon, Ájax, Pátrocles, Diomedes, Menelau, Nestor, Ulisses - do lado dos Aqueus Heitor, Páris, Príamo, Hécuba e Andrómaca) ”. (FONSECA, 1998, p. 5)

Na Ilíada, a principal representação de areté aparece na figura de Aquiles, um

[...] herói modelo, nobre, valente e corajoso, o melhor aristós - entre todos [...]. Para além do guerreiro valoroso, valente, corajoso e honrado, Aquiles é o protótipo do perfeito cavaleiro da época homérica, arcaica, cortês, cavalheiresco, de boas maneiras, fino e polido no trato social. Mas se é em Aquiles que melhor se realiza este ideal, é evidente que não se chega lá espontaneamente, antes se pressupõe uma educação apropriada. (FONSECA, 1998, p. 5)

Portanto, a 
guerreiro, a eloquência e a persuasão, e, acima de tudo, a heroicidade, entendida esta como a fusão da força com o sentido moral. A esta concepção de aretê se juntou, não pela etimologia mas pelo sentido, agathós. Ser agathós é ser nobre, é ter força ou coragem ou habilidade para qualquer fim superior. (FONSECA, 1998, pp.7-8)

Enfim, o conceito de areté representa um ideal que serve de modelo para a formação do homem "perfeito", através do aperfeiçoamento do corpo, da alma, da oratória, das boas ações e da ética.

Nesse sentido, podemos investigar essa concepção de educação presente na tradição grega, a partir das obras de Homero, para compreendermos a pedagogia enquanto exemplo. De acordo com Fonseca uma "pedagogia fundada no exemplo vivo ou no exemplo mítico, a pedagogia do paradigma. O herói prototípico institui-se como modelo exemplar a seguir; imitar os heróis, o que desperta a emulação, para, como eles, ser herói, possuidor da aretê heroica”. (FONSECA, 1998, p.9)

Segundo Fonseca (1998, p.4)

[...] o tema da virtude - aretê - como tema central e núcleo fundamental à volta do qual gira toda a discussão acerca da questão educativa, da Paideia, - porque educar, é, em última análise, tornar melhor o homem, aperfeiçoá-lo, torná-lo mais virtuoso.

Além das obras atribuídas a Homero, nas obras Teogonia e dos Trabalhos e Dias, de Hesíodo, podemos encontrar um outro sentido do conceito de areté, através do ideal de humanidade como o "homem que trabalha [...] e o trabalho é fonte de dignidade e conduz à superioridade". (FONSECA, 1998, p.9). Portanto, aparece em Hesíodo a ideia de que o trabalho conduz a areté.

Por fim, a educação na Grécia arcaica se configura por meio de um paradoxo, pois se baseia no pensamento mítico para explicar a realidade, e, portanto, conceber o ideal de ser humano que deve ser formado no mundo grego, através da areté. Porém, a explicação mítica concebe a realidade, por meio de fatores externos aos seres humanos, valorizando as questões 
sobrenaturais e mágicas para tal fim, e é nesse processo histórico que os nobres gregos criaram uma Paideia.

\section{A transição da educação homérica para educação clássica.}

O pensamento filosófico surge por volta do século VI a.C., nas polis gregas, porém a ruptura com o pensamento mítico não acontece de forma completa e imediata, já que o surgimento de uma nova explicação de mundo, não significa o desaparecimento por completo do mito. Portanto, o mito sobrevive através das tradições culturais de um povo.

\section{Segundo Nunes (2017, p.3), a}

[...] educação arcaica grega baseia-se na poesia, utilizase da rapsódia e embasa-se na proposição intencional de uma educação para a virtude, para a admiração dos heróis e de seus feitos. Essa educação moral era a sustentação da educação aristocrática ateniense. Nos séculos IV a.C. Platão e Aristóteles buscarão uma nova forma de embasamento da significação racional da vida, ao intentar definir os fundamentos éticos e políticos para o sentido da vida humana em sociedade. Uma educação centrada na Ilíada e na Odisséia, que reporta a Homero, era a prática de formação do homem aristocrata ateniense, até a interposição dos filósofos matriciais Platão e Aristóteles! O fundamento desta educação aristocrática girava ao redor do conceito de areté ou de virtude.

Dessa forma, para realizarmos o nosso estudo sobre a história da educação grega, precisamos compreender as condições materiais, ou seja, as condições econômicas, sociais, políticas e históricas da transição da Paideia homérica para a Paideia política.

\section{A educação no período pré-socrático}

O pensamento filosófico surge nas colônias gregas do mediterrâneo, tais como Mileto e Éfeso. Estas cidades-estados eram entrepostos comerciais, ponto de encontro de caravanas vindas do oriente, sobretudo, da Mesopotâmia e Persa. Por esses motivos, nas cidades conviviam pessoas de diferentes culturas, e, por vezes, de forma harmoniosa, pois o interesse comercial criava condições materiais para os povos que aí se encontravam, 
sobretudo os gregos fundadores das cidades, fossem também bastante tolerantes. (MARCONDES, 2008)

Os filósofos da escola de Mileto, como Tales de Mileto, procuraram explicar a realidade, através da investigação do mundo natural (a physis, daí o nosso termo física), e procuraram compreender as leis naturais do mundo. Nesse sentido, segundo Marcondes (2008), a "chave da explicação do mundo de nossa experiência estaria então, para os pensadores, no próprio mundo, e não fora dele, em alguma realidade misteriosa e inacessível". (MARCONDES, 1998, p.21).

Os principais filósofos pré-socráticos frequentaram a escola Jônica e as escolas Italianas. A escola Jônica, conhecida também naturalismo, era formada pela escola de Mileto, a qual tinha como principais representantes: Tales de Mileto, Anaximandro, Anaxímenes, Heráclito de Éfeso e Xenófanes de Colofon. Além dessa escola, podemos destacar também as escolas italianas: os pitagóricos e Eleatas.

Estes filósofos entendiam que era possível compreender a realidade a partir do mundo natural. Para isso, era preciso conhecer a physis (teoria da natureza), a causalidade (a conexão causal entre determinados fenômenos naturais), a arqué (elemento primordial), o cosmo (universo racionalmente ordenado), o logos (discurso racional, argumentativo, em que as explicações são justificadas e sujeitas à crítica) e o caráter crítico (as teorias devem evitar o dogmatismo, por meio das reformulações das mesmas).

Enfim, nesse momento da história grega, os mitos já não eram considerados suficientes para explicar a realidade, pois ocorreu um deslocamento das explicações calcadas nos valores sobrenaturais e mágicos para as explicações naturais e lógicas da realidade.

\section{A educação no período socrático}

Como era possível educar as pessoas para conhecer a realidade por meio da filosofia? Quais foram as mudanças com relação o sentido de pensar a realidade entre os filósofos pré-socráticos para os filósofos socráticos? Qual era a Paideia socrática? 
Para compreendermos a emergência do pensamento socrático, precisaremos pesquisar as condições materiais que favoreceram a mudança da visão de mundo dos gregos, por meio da investigação das mudanças políticas, econômicas, sociais e culturais do século V a.C. e as relações com a questão sobre a educação grega.

Com relação ao contexto econômico do período da Grécia clássica, a intensificação do comércio nas cidades-estados gregas e a intensificação das relações dos gregos com outros povos do mundo antigo, provocou uma alteração na organização política das pólis gregas, e também nos valores culturais da época.

Isso fica claro, quando observamos a formação da liga de Delos (477 a.C.), cujo grupo de comerciantes poderosos da sociedade ateniense, uniram-se com objetivo de adquirem vantagens nas trocas de mercadorias, e o resultado desse processo histórico foi um momento de estabilização política na sociedade grega, da classe mercantil, envolvida com as atividades comerciais e a expansão marítima, a qual começou a influenciar na política da época nas cidades-estados gregas.

De acordo com Nunes (2017b, p.61),

[...] no mundo conhecido de então Atenas era uma cidade-estelar, parecia que por si cruzam todas as rotas e destinos, notáveis aos negócios se faziam nas casas e o porto de Atenas, o Pireu, era repleto de produtos mercantis e de escravos de todo mundo. Esse ambiente de efervescência econômica e riqueza ou diversidade cultural era celeiro de muitas ideias, a base espiritual da originalidade e do cosmopolitismo de toda Grécia. Pela cidade transitavam homens livres, homens de negócios, com seus produtos e escravos, os viajantes, muitos aventureiros, legiões de mercenários etc. Outros naturalistas, retóricos, poetas, artistas, alguns sábios, e taumaturgos, outros sofistas, educadores, rapsodos, emergentes de toda a espécie, moralista, pregadores, saudosistas, músicos, escritores, militares, um universo de novidades e de ideias, de crenças e de utopias em disputa na riqueza e na plena liberdade recém inaugurada pela vida política democrática de Atenas.

No caso de Atenas, as reformas políticas iniciadas por Sólon (594 a.C.), levadas adiante por Clístenes (507 a.C.), introduz as primeiras regras democráticas no mundo antigo, chegando até o primeiro governo de Péricles 
e Efialtes (462 a.C.), considerado o momento de esplendor da democracia grega. (MARCONDES, 2008, p.41)

Nesse sentido, o surgimento da democracia grega, representa:

[...] exatamente a possibilidade de se resolverem,
através do entendimento mútuo, e de leis iguais para
todos, as diferenças e divergências existentes nessa
sociedade em nome do interesse comum. As
deliberações serão tomadas assim em reuniões de
cidadãos, as assembleias. [...]. Não se dispõe mais da
força, dos privilégios, da autoridade divina [...] A
linguagem precisa ser racional, as discussões
pressupõem a apresentação de justificativas,
argumentos, sendo abertas a interpretação, ao
questionamento

Dessa forma, podemos afirmar que a partir do momento em que a democracia ateniense se instituiu enquanto política hegemônica da pólis de Atenas, ocorreu o deslocamento do pensamento dos filósofos pré-socráticos, preocupados com as explicações da realidade natural, para uma valorização da necessidade de compreender a realidade humana, pois o objetivo central dos cidadãos ateniense era participar da assembleia, participar da política, portanto, exercer a sua cidadania.

Segundo Vernant (1984, p. 34-36),

[...] o aparecimento da pólis constituiu, na história do pensamento grego, um acontecimento decisivo. [...] $\mathrm{O}$ que implica o sistema de pólis é primeiramente uma extraordinária preeminência da palavra sobre todos os outros instrumentos de poder. Torna-se o instrumento político por excelência, a chave da autoridade no Estado, o comando e de domínio sobre outrem. [...] A palavra não é mais o ritual, a formula justa, mas o debate contraditório, a discussão, a argumentação. [...] A arte política é essencialmente exercício da linguagem.

Assim, os homens atenienses se apropriaram do conhecimento filosófico, com o objetivo de participarem da vida política, para isso era preciso expor suas ideias e convencer as pessoas sobre suas opiniões de forma racional, lógica, sistemática e objetiva.

Dessa forma, os filósofos adquiriram uma importância pedagógica na formação dos homens e o conhecimento produzido pela filosofia se torna fundamental para legitimar essa discussão. Perguntas, como o que é verdade? Quais os princípios da razão? Tornaram-se corriqueiras. 


\section{A educação dos Sofistas}

Para compreendermos a emergência de uma filosofia na pólis de Atenas, durante o século $\mathrm{V}$ a.C., devemos nos ater as diferenças de explicação da realidade concebidas pelos sofistas e a filosofia de Sócrates e Platão, principalmente.

Nesse sentido, os sofistas começaram a demostrar seus pensamentos na ágora de Atenas, em um momento de mudanças políticas, a partir da passagem da tirania e da oligarquia para democracia.

Os Sofistas eram considerados mestres da retórica e oratória. Eles tinham o objetivo de formar cidadãos para a participação política. Porém, os sofistas não formaram uma escola ou um grupo homogêneo, mesmo que muitos estudiosos da história da filosofia considerem os sofistas como os primeiros educadores na Grécia antiga.

Os sofistas mais conhecidos foram Protágoras de Abdera (490 - 421 a.C.), Górgias de Leontinos (487 - 380 a. C.) Hípias de Elis, Licofron, Pródicos, que inclusive teria sido mestre de Sócrates. (MARCONDES, 2008, p.43)

$\mathrm{O}$ pensamento sofista se fundamenta no humanismo, na subjetividade e no relativismo, por meio de uma concepção filosófica segundo a qual o conhecimento é relativo a experiência humana concreta do real, e a verdade resultado apenas de nossas opiniões sobre as coisas e do consenso que se forma em torno disso. A verdade é, portanto, múltipla, relativa e mutável.

Por fim, o pensamento sofista valoriza o conhecimento produzido a partir da interpretação subjetiva do real e a Paideia sofista tinha como objetivo vender a educação para formar cidadãos que pudessem participar a política.

\section{A educação na concepção de Sócrates}

Sócrates opõe-se aos sofistas, mesmo tendo estudado com Pródicos, no que diz respeito à necessidade de produzir o conhecimento como uma 
verdade única sobre a natureza e a humanidade, afastando-se das opiniões, crenças e do senso comum para buscar a definição das coisas.

A dúvida tem um papel central no pensamento de Sócrates, pois é através dos questionamentos das respostas que os seres humanos elaboram sobre o conhecimento produzido a partir do senso comum, que é possível chegar a uma verdade única.

Nesse sentido, a verdade pode ser atingida por meio da pergunta, da reflexão e da definição de alguma coisa e não pela mera transmissão de um determinado conteúdo. Esse pensamento pode ser ilustrado na célebre questão socrática “o que é?”. Portanto, segundo Sócrates é na dialética entre a pergunta e a resposta que se caminha rumo a verdade.

Dessa forma, para Sócrates a educação só pode ser resultado de um processo de reflexão do próprio indivíduo, que descobrirá, a partir da experiência aquilo que busca. Trata-se de um exercício intelectual em que a razão humana deve descobrir por si próprio aquilo que busca, ou seja, como o próprio Sócrates afirma "conhece-te a ti mesmo". Assim, a busca é a essência do homem, do homem como político, enquanto habitante da pólis.

Para Sócrates, podemos chegar a verdade por meio do método maiêutico. De acordo com Marcondes (2008, p.48), esse método não consiste em

[...] "transmitir um saber pronto e acabado, mas fazer com que o outro indivíduo, seu interlocutor, através da dialética, da discussão no diálogo, dê à luz a suas próprias ideias". [...]. A dialética socrática opera inicialmente através de um questionamento das crenças habituais de um interlocutor, interrogando-o, provocando-o a dar respostas e a explicar o conteúdo e sentido dessas crenças. Em seguida, frequentemente utilizando-se de ironia, problematiza essas crenças, fazendo com que o interlocutor caia em contradição, perceba a insuficiência delas, sinta-se perplexo e reconheça a sua ignorância. [...] É este o sentido da célebre fórmula socrática "Só sei que nada sei", a ideia de que o reconhecimento da ignorância é o princípio da sabedoria. A partir daí o indivíduo tem caminho aberto para encontrar o verdadeiro conhecimento (episteme), afastando-se do domínio da opinião (doxa). 
Por fim, o método socrático propõe um questionamento do senso comum, das crenças e opiniões que temos, consideradas vagas, imprecisas, derivadas da experiência, e, portanto, parciais e incompletas, e por meio da maiêutica podemos chegar ao conhecimento real, racional da condição humana.

\section{A educação platônica}

Platão nasceu em Atenas, por volta de 428 a.C., e era membro de uma família aristocrática, foi seguidor de Heráclito e Sócrates. Em 387 a.C. inaugura a Academia, o primeiro curso superior da antiguidade Clássica. Descendia dos antigos reis de Atenas, de Sólon e era sobrinho de Crítias (460/403) e Cârmides, dois dos "Trinta Tiranos", que governaram Atenas em 404 a.C. Lutou na Guerra do Peloponeso entre 409 e 404 a.C., e a admiração por Sócrates, que conheceu em algum momento desse período, foi decisiva em sua vida.

Segundo Nunes (2017a, p.15)

Platão opõe-se à educação poética, de tradição homérica, de base mitológica, e a define como paidéia arcaica, mas propõe, no conjunto de seu ofício, um novo ideal ético, estético e político, pelo caminho igualmente salutar da educação, agora definida como uma nova educação, ou seja, a filosofia como uma nova paideia.

Segundo Marcondes (2008), a obra de "Platão pode ser entendida como uma longa reflexão sobre a decadência da democracia ateniense, de seus valores e ideais, de seu modelo, o contexto político que afinal condenou seu mestre Sócrates, 'o mais sábio dos homens', à morte”.

No contexto da decadência da democracia ateniense, Platão destaca algumas questões filosóficas, como o que significa democracia? O que significa ensinar?

A grosso modo, podemos dividir o nosso estudo sobre as obras de Platão em três fases distintas. 
A primeira fase dos textos de Platão diz respeito aos diálogos socráticos, a qual ocorre a exposição da visão de Sócrates, a partir de dois núcleos: o primeiro na defesa de Sócrates. Segundo Nunes (2017b, p. 55),

ao escrever A apologia a Sócrates Platão insiste em buscar a resposta ao veredicto que o condenara, seu tema central de militância e ação político-acadêmica pode ser resumido no seguinte princípio - Sócrates nem se corrompera a juventude nem desacreditava dos deuses

O segundo núcleo composto pelas obras "Eutífron, o Críton, o Laques, o Cármides, o Hípias Maior e Hípias Menor, o Protágoras, o Górgias, o Lísis, e finalmente, o Íon. Quase sempre temas socráticos: a amizade, a temperança, a piedade, a coragem.” (NUNES, 2017b, p. 55)

Na segunda fase Platão foi influenciado pelos Pitagóricos e Eleatas, no que diz respeito à elaboração da teoria das formas ou ideias, por meio valorização do estudo da geometria. É nesse momento que Platão elabora a doutrina sobre as ideias, presentes nos diálogos o Menon, a República, Fédon, o Eutidemo, o Político e o Banquete e as cartas o Crátilo e Menexeno.

E, por fim, a terceira fase, a qual realiza a crítica a Sócrates, sobretudo, no que diz respeito ao método de análise, pois a reflexão proposta por Sócrates é insuficiente para a produção de um conhecimento verdadeiro, já que falta uma teoria.

Nesse sentido, segundo Marcondes (2008, p.56), a

[...] crítica de Platão a Sócrates diz respeito sobretudo a concepção de filosofia como método de análise, que, embora Platão considerasse um elemento importante da reflexão filosófica, seria no entanto insuficiente para caracterizá-la. Seu principal argumento era que o método necessita, para aplicação correta e eficaz, de um fundamento teórico que estabeleça exatamente os critérios segundo os quais o método é aplicado de forma correta e eficaz. [...] É necessário desenvolver uma teoria sobre a natureza dos conceitos e das definições a serem obtidas. É esse papel da famosa teoria platônica das ideias ou das formas, que pode ser considerada o início da metafísica clássica. 
Desse modo, a filosofia platônica tem uma preocupação em atingir o conhecimento verdadeiro, por meio da superação da reflexão filosófica, por meio da elaboração de um sistema, baseado da totalidade do conhecimento. De acordo com Nunes (2017b, p.75), Platão

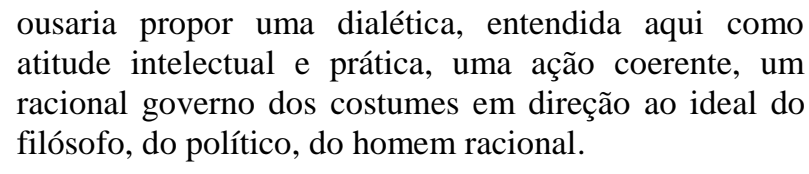

Dessa forma, segundo Platão a reflexão pode ocorrer por meio dos diálogos, na busca de um conhecimento científico, portanto, verdadeiro e legitimo, moral e político. Assim, para Platão o conhecimento tem a função pedagógica de se identificar com o bem.

Para Platão o objetivo da filosofia é superar o senso comum, por meio de um discurso verdadeiro, universal e racional, que se afaste do mundo sensível e se aproxime do mundo das ideias, portanto, próximo da perfeição.

A questão do conhecimento tem destaque na obra de Platão, pois se relaciona com a visão do bem. Dessa forma, o método da filosofia platônica tem o objetivo de atingir o ideal em todas as áreas pela superação do senso comum, estabelecendo o que será aceito por todos, por meio da universalidade da razão.

Dessa forma, no método dialético a filosofia é uma resposta para uma situação de injustiça, colocada como uma solução de um problema na sua totalidade, com o objetivo de promover a transformação da realidade, e, claro, da decadência da pólis de Atenas.

Segundo Nunes (2017b, p.77), a filosofia de Platão tem como o objetivo de

constituir um sistema, um todo ordenado de conceitos, de categorias e de teorias integradas e lógicas. [...] Platão advoga que a paideia política, o amplo processo de formação do homem, através da filosofia, deve encontrar inspiração na doutrina da origem da alma, de modo a não se deixar enganar pelos falsos preceptores, pelos demagogos, pelos sofistas e por toda espécie de charlatões que pululavam na desordeira Atenas do seu tempo. 
Para Platão a filosofia é uma forma de saber que possui um caráter essencialmente ético-político, pois a teoria filosófica é imutável, eterna. Uma consequência da filosofia Platônica e que ela se afasta da experiência imediata e concreta.

Nesse sentido, os mitos da Linha dividida e da Caverna, encontrados no livro a República, estabelece a relação entre o conhecimento da realidade com a dimensão ético-política e a motivação político-pedagógico do filósofo. Assim, nestas alegorias Platão propõe como os seres humanos podem superar e se libertarem das visões parciais e incompletas, ou seja, das ilusões, por meio da teoria platônica da alma, ou seja, através da Paideia platônica.

Por fim, no século de Platão, amplia-se a compreensão do Homem para o âmbito do Estado e da Educação, por meio da Paideia clássica, compreendida aqui como uma teoria filosófica que deve ser ensinada aos homens, pois a pólis de Atenas deve ser governada pelos homens bons, aristocratas, que conduzam as decisões de forma racional, universal, total e justa.

\section{Considerações finais}

A herança grega mais importante é a de que a Paideia Grega é indispensável para a compreensão de todo tipo de conhecimento e da educação. Não se compreende a trajetória da educação ocidental sem compreender a Paideia Grega e a Formação do Homem Grego.

Nesse sentido, investigamos a história da gênese da educação grega, por meio do ideal de homem que deveria ser formado durante o período homérico até o período clássico, passando pela areté até a Paideia. Assim, concluímos que no período primitivo e no período clássico grego, constituiu-se o ideário do homem heroico e político, pois todo o povo que atinge um certo grau de desenvolvimento sente-se historicamente inclinado à prática da educação. A educação é o princípio por meio do qual a comunidade humana conserva e transmite a sua peculiaridade física e espiritual. Dessa forma, só homem consegue conservar e propagar a sua 
forma de existência social e espiritual por meio das forças pelas quais a criou, quer dizer, por meio da vontade consciente da razão.

Por fim, a podemos observar que a Paideia não é propriedade individual, mas pertence por essência à comunidade, à história, política, economia e cultura de um povo em um determinado lugar.

\section{Referências}

SILVA, Roseli G. Amaral da. A formação do homem ideal: o herói grego e o cristão. 2008.

FAZENDA, I. (org) Metodologia da Pesquisa Educacional. $3^{\circ}$ ed. São Paulo: Cortez, 1994.

FONSECA, Maria de Jesus. A Paideia grega revisitada. Milelenium, 1998.

HABERMAS, J. Discurso filosófico da modernidade. São Paulo: Martins Fontes, 2000.

HOBSBAWM, Eric J. A invenção das tradições. $9^{\circ}$ ed. São Paulo: Paz e Terra, 2014.

JAEGER, Werner. Paidéia: a formação do homem grego. 6.ed. São Paulo: Editora WMF Martins Fontes, 2013.

MARCONDES, Danilo. Iniciação à história da filosofia: dos pré-socráticos a Wittgenstein. 12.ed - Rio de Janeiro: Jorge Zahar Ed., 2008.

NUNES, César. Da Filosofia do Amor ao Amor à Filosofia. Librum Edições \& Editora Brasílica, Campinas, 2017, a.

NUNES, César. Platão e a dialética entre a filosofia do amor e amor à filosofia. Campinas, SP: Librum Editora e Editora Brasílica, 2017, b. 
SÁNCHEZ GAMBOA, S. Pesquisa em Educação: métodos e epistemologias. Chapecó, SC: Argos, 2012.

SAVIANI, D. Educação: do senso comum à consciência filosófica. São Paulo: Cortez, Autores Associados, 1980.

VERNANT, Jean-Pierre. As origens do pensamento grego. São Paulo, Difel, 1984. 